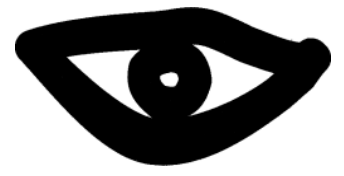

\title{
À descoberta de sinergias invisíveis: desvendando a interculturalidade na migração
}

\author{
Maria Paula Neves, María del Carmen Arau-Ribeiro, Luísa Maria Campos, \\ Maria Hermínia Barbosa, Nelson Clemente Oliveira \\ Instituto Politécnico da Guarda, Portugal
}

\begin{abstract}
Resumo
Neste artigo, propomos divulgar os resultados de um estudo sobre a dinâmica do apoio ao migrante disponível no distrito da Guarda, Portugal, inserido na região Centro Interior, descrita pelo Alto Comissariado das Migrações (ACM) como um território extenso pouco povoado, embora considerado um povoamento não disperso, aglomerado em várias sub-regiões. Já que os resultados refletem pouca interação com a comunidade local, concentrando-se antes no elo inicialmente estabelecido com os agentes institucionais, pretende-se organizar encontros com a comunidade local paralelamente a entrevistas com os próprios migrantes, envolvendo desta forma entidades, migrantes e académicos no objetivo comum de melhor se conhecerem, refletindo sobre o possível intercâmbio de ideias e práticas em conjunto.

Palavras-chave: interculturalidade, integração, migração, Instituto Politécnico da Guarda, Portugal
\end{abstract}

\section{Introdução}

A migração em si é uma preocupação por todo o mundo já que envolve uma deslocação não só de pessoas mas também de culturas. A relevância deste tema provém do facto de que ter havido uma alteração na nomenclatura tradicional, reunindo os três conceitos - imigração, emigração e migração - nesta última forma lexical; aos vocábulos derivados do verbo migrar juntam-se todos os sentidos antes atribuídos aos outros (AMI, 2007). Desta forma, quem muda de território geográfico é migrante, seja a mudança para dentro ou para fora de um país, para residência de pouca ou longa duração.

No que diz respeito ao território nacional no âmbito das migrações, de entre 31 países e de acordo com a avaliação do Índice de Políticas de Integração de Migrantes (MIPEX - Index de Políticas de Integração de Migrantes), Portugal oferece as melhores condições de acesso ao mercado de trabalho, bem como as melhores bases legais para a "construção de uma cidadania comum” (ACIDI, 2011). Este apoio à cidadania na Lei da Nacionalidade (2006) é sustentado ainda na Lei de Imigração (2007) que inclui apoio à residência de longa duração, destacando-se dos outros países.

Com um orçamento de 50 milhões, a Europa preparase para receber nos próximos anos entre 20.000 e 40.000 refugiados dos países da Eritreia e Síria e destes, entre 700 e 1.700 em Portugal (Falcão e Dinis, 2015; Pop, 2015). De acordo com a Comissão Europeia e especificamente em Portugal, reconhecem-se "quatro pilares de ação a médio prazo identificados na Agenda Europeia para as Migrações: o combate às causas profundas da imigração irregular; a gestão das fronteiras; a política de asilo; e a migração legal” (Governo de Portugal, 2015).

Assim, as infraestruturas e os agentes já existentes no país irão receber novos migrantes, cujo futuro se alia a um conhecimento profundo do funcionamento das mesmas. O Alto Comissariado para as Migrações (ACM) já está a preparar o terreno para esta realidade futura, com a recente inclusão da Rede do Ensino Superior para a Mediação Intercultural (RESMI), tendo especificamente já oferecido apoio para a formação de docentes do ensino superior em Mediação Intercultural (MI), desenvolvido ao longo de uma semana em Madrid e Lisboa no verão de 2014 e coordenado por Carlos Giménez Romero, catedrático de Antropologia Social da Universidade Autónoma de Madrid, que também dirige o Programa de Migração e Multiculturalidade.

A definição de Interculturalidade em que a RESMI se apoia é dele: "Modalidade de intervenção de terceiras partes, em e sobre situações sociais de multiculturalidade significativa, orientada para a consecução do reconhecimento do Outro e da aproximação das partes, a comunicação e a compreensão mútua, a aprendizagem e o desenvolvimento da convivência, a regulação de conflitos e adequação institucional, entre atores sociais ou institucionais etnoculturalmente diferenciados. [No original: Entendemos la Mediación Intercultural -o mediación social en contextos pluriétnicos o multiculturales - como una modalidad de intervención de terceras partes, en y sobre situaciones sociales de multiculturalidad significativa, orientada hacia la consecución del reconocimiento del Otro y el acercamiento de las partes, la comunicación y comprensión mutua, el aprendizaje y desarrollo de la convivencia, la regulación de conflictos y la adecuación institucional, entre actores sociales o institucionales etnoculturalmente diferenciados.] (Giménez Romero, 1997, p. 142).

Com este encaminhamento e preparação na formação, o grupo de investigação do Instituto Politécnico da Guarda (IPG) foi criado, reunindo docentes /

/investigadores das áreas de Sociologia e Saúde bem como três professores de Línguas e Culturas com formação e experiência em língua e cultura inglesa, francesa, alemã, portuguesa e espanhola. Das três vertentes da RESMI apoiadas pelo ACM - a Educação, 
a Saúde e o Território - a última constitui o âmbito de investigação do IPG. O Grupo do Território (GT) da RESMI reúne as Instituições de Ensino Superior interessadas, com outros projetos já desenvolvidos na área. Visto a inserção na rede promover a partilha de saberes e metodologia de trabalho, a investigação reveste-se de metodologias já comprovadas e o benefício da experiência dos colegas.

\section{Métodos e Procedimentos}

Com o objetivo de estudar os elos entre os povos migrantes e as infraestruturas governamentais e ONG, estabelecer a metodologia a empregar foi uma preocupação premente que se resolveu através de uma série de estratégias, métodos e procedimentos. Nomeadamente, para satisfazer os objetivos do estudo, identificando a situação e as políticas locais de interculturalidade, foi preciso primeiro entender e conceptualizar a noção de território. Este conceito vasto das ciências sociais é uma construção social que se define pela localização. Tem ainda uma dupla conotação de exclusão (do local) e de proteção (relativa ao local) através dos processos de identificação e apropriação (Ribeiro, 2015).

Através de uma pesquisa documental, deram-se a conhecer os traços da política nacional sobre a migração para poder analisar a sua aplicação a nível local.

Foi elaborado um guião a ser usado nas entrevistas às instituições, o qual teve em atenção a legislação existente, a noção de território e conceitos provenientes da investigação em ciências sociais.

Antes da sua aplicação, o guião, como instrumento do método de investigação, foi enviado aos restantes núcleos da RESMI para ser testado.

Uma vez recolhidos os dados desta investigação-ação, foram analisadas as caraterizações objetivas e quantitativas bem com as narrativas biográficas e constatações mais subjetivas, valorizando da melhor forma as metodologias participativas de pesquisa/ investigação e trabalho com estas instituições.

\section{Participantes}

A equipa de cinco doentes colaborou na investigação, recebendo formação, criando instrumentos de prospeção e de recolha de dados, executando o trabalho de campo e analisando os resultados.

As entrevistas até agora levadas a cabo foram conduzidas com quatro agentes que proporcionam auxílio na receção e integração dos migrantes na zona abrangida. Nestes encontros agendados antecipadamente e deixando claro o objetivo da entrevista, participaram sempre dois membros da equipa de investigação para melhor entenderem todas as facetas do diálogo estabelecido. Assim, os dados foram recolhidos a partir da colaboração com os Centros Locais de Apoio à Integração do Imigrante (CLAII) da Guarda e de Figueira de Castelo Rodrigo, a Rede Local de Intervenção Social (RLIS) da Guarda e a Cruz Vermelha de Vilar Formoso.

\section{Levantamento de contactos}

A prospeção do território consistiu num levantamento de instituições e seus respetivos contactos. Sendo já do conhecimento da equipa a existência do Serviço de Estrangeiros e Fronteiras (SEF) e da Rede Local de Intervenção Social (RLIS), para se proceder ao levantamento e à identificação de outras organizações e projetos, no âmbito das migrações, na área geodemográfica do distrito da Guarda, recorreu-se, numa primeira fase, a uma pesquisa na web. Assim, pesquisou-se usando diferentes combinações das palavras migrações, instituições, apoio social, apoio humanitário, instituições religiosas. Depurada a informação resultante da pesquisa salienta-se a que se segue.

Na página Web do Alto Comissariado para as Migrações (ACM) - http://www.acidi.gov.pt/ - foi possível identificar projetos e programas em vigor no distrito. Salientam-se, dentro do programa, escolhas, o projeto Tu Decides +, na Guarda, em que a entidade promotora e gestora é o Núcleo Desportivo e Social (NDS) e o projeto Convergir para a Igualdade, em Figueira Castelo Rodrigo, sendo a entidade promotora e gestora a Fundação D. Ana Paula Águas Vaz de Mascarenhas e Garcia e Doutor Álvaro Augusto Garcia Ainda na página do ACM encontrou-se implementado nos Municípios de Figueira Castelo Rodrigo e de Sabugal, o Programa Mentores.

No que respeita aos Centros Locais de Apoio à Imigração (CLAII) - http://www.acidi.gov.pt/esimigrante/servicos/centros-locais-de-apoio-a-

integracao-de-imigrantes---claii - foram identificados o CLAII Figueira Castelo Rodrigo em funcionamento na Câmara Municipal de Figueira de Castelo Rodrigo e o CLAII Guarda na Cáritas Diocesana da Guarda.

Numa perspetiva social e humanitária revelaram-se também úteis as páginas das Câmaras Municipais, da Segurança Social, da Procuradoria-Geral da República, em particular relativamente ao trabalho das Comissões de Proteção de Crianças e Jovens (CPCJ), Cáritas Diocesana e Cruz Vermelha de Vilar Formoso, Figueira de Castelo Rodrigo e Guarda.

Identificou-se, ainda, a ADM Estrela - Associação de Desenvolvimento e Melhoramentos www.admestrela.pt - por ser parceira e sócia 
fundadora da HUSCIE (Humanitarian and Social Committee in Europe).

\section{Instrumentos}

Sendo o primeiro estudo do tipo a ser elaborado nesta zona, foi criado, como já referido, um guião de entrevista para ser usado no contacto com os agentes transformadores no terreno e recolha sistemática de dados no momento da entrevista.

O guião de entrevista foi elaborado com base em conhecimentos de Sociologia e das tradições e tendências do fenómeno da migração. Para a elaboração do guião partiu-se da ambiguidade de definição que o conceito "integração" encerra na teoria sociológica. Para Boudon (1990), este tanto pode designar um estado de forte interdependência ou coerência entre elementos, como o processo que conduz a esse estado, podendo, nesta perspectiva, ser aplicado tanto a um sistema social como à relação indivíduo/sistema social. Posição similar é defendida por Pena Pires (1999; 09) para quem pode ser articulado em dois contextos: "O termo integração é correntemente usado na literatura sociológica para designar no plano micro, o modo como os actores são incorporados num espaço social comum, e no plano macro, o modo como são compatibilizados diferentes subsistemas sociais”. Também Rocha-Trindade (1995) reitera o caráter interativo deste processo pois, para a autora, o ajustamento do indivíduo ao novo meio não é um processo unidirecional mas flexível e bidimensional que implica não só a adaptação dos recém-chegados à sociedade de acolhimento, mas também a maleabilidade e capacidade de transformação desta, para a recepção e "integração" de novos grupos. A mesma autora defende que para aferir a integração de migrantes numa dada sociedade, o modelo mais utilizado na sociologia é o da «Diferenciação Estrutural». Segundo este modelo, as diferenças relativamente ao processo de ajustamento dos migrantes são função de um conjunto de variáveis composicionais, isto é, segundo este modelo a variável dependente (indicador de adaptação) é influenciada, determinantemente, por características de ordem: sociográfica (sexo, idade, estado civil, composição do agregado familiar, local de residência); social (nível de instrução, formação profissional, origem étnica, religião, conhecimento da língua do país de acolhimento); económicas (participação na força de trabalho, estatuto socioprofissional e rendimento). Estudos realizados com base neste modelo parecem indiciar que o nível de instrução é a variável independente que mais influencia o estatuto ocupacional, a mobilidade social e o rendimento dos emigrantes e, em última análise a variável dependente, isto é, integração.

De forma geral, o guião procura sistematizar os dados mais objetivos como a identificação da instituição e a caraterização dos migrantes, bem como os dados mais suscetíveis de interpretação, como as alterações sociais desencadeadas pela inclusão de migrantes no distrito.

Quanto à interação dos migrantes com a área da economia/finanças, tenta detetar-se a necessidade de recorrer a intérpretes e a outras estratégias de intercomunicação ou, mais especificamente, à oferta de auxílio na elaboração do IRS ou no aluguer ou na compra de casa/imobiliário. Questiona-se se a migração num dado território resultou em mais procura e até oferta de tradução/ interpretação/ atividades culturais em outras línguas.

Procura-se ainda qualificar a integração dos migrantes no mercado de trabalho. Além de descrever as atividades e/ou as empresas que contratam migrantes e procura-se saber se a migração é sazonal ou não.

Já relativamente às áreas da família e da escola, procura-se se a textura do tecido social sofreu alterações consoante a composição familiar do migrante que se desloca com todo ou só parte do agrupamento familiar. No que diz respeito ao sistema educativo, indaga-se se há questões culturais a resolver, bem como eventuais diferenças nos feriados e, noutro plano, níveis de escolaridade e, como resultado, discrepâncias nas equivalências a atribuir. Questões educacionais podem também ter impacto na área educação/ trabalho, onde a preparação académica pode não corresponder ao cargo atualmente desempenhado.

Ainda em termos socioculturais, pretende-se na entrevista conhecer as eventuais associações de migrantes ou os locais onde se reúnem habitualmente, sendo estes clubes, cafés, bares ou restaurantes. Procura-se a concentração residencial ou guetização, indícios de fenómenos de reagrupamento familiar, de religião, locais de culto e práticas religiosas. Para finalizar, carateriza-se a relação dos migrantes com as comunidades locais, que pode abarcar desde uma relação positiva até uma de invisibilidade, ostracismo e mesmo de conflitos.

\section{Resultados}

Através da descrição das dinâmicas e experiências locais, procurou-se a caraterização da interculturalidade. Encontraram-se agentes locais que se dedicam a garantir que todas as pessoas sejam tratadas por igual, reconhecendo que, em relação aos migrantes, há uma preocupação um pouco maior pois não estão integrados culturalmente. 
As associações contactadas têm um papel de mediador e fazem atendimento e acompanhamento aos imigrantes contribuindo para uma melhor e mais rápida integração na sociedade. Existe uma ligação com outras entidades como a Segurança Social, o hospital (Ação Social), escolas, a GNR e Centros Paroquiais.

No que diz respeito à RLIS, no projeto piloto sediado no Centro de Formação, Assistência e Desenvolvimento da Guarda (CFAD) com duração de meio ano, que visa responsabilizar as pessoas, tornando-as autossuficientes, dos atendimentos por mês, que quase quadruplicaram desde a sua criação em janeiro de 2015 com uma subida de 80 para $240-310$ por mês, poucos são migrantes. Estes entram em contacto com a RLIS e também com a Cruz Vermelha através da linha de emergência nacional 144. Nos casos de tráfico humano, estes são encaminhados para as autoridades policiais.

Relativamente às origens dos povos migrantes, as nacionalidades que se destacam são a ucraniana, a moldava, a brasileira, a espanhola, a romena e, mais recentemente, a búlgara, e ainda a bengali e a paquistanesa, bem como refugiados da Síria, do Congo, dos Camarões e da Nigéria a receberem auxílio na cidade da Guarda, num total de 197 indivíduos.

As religiões distribuem-se entre sikh, ortodoxa, judaica, católica e alguma representação islâmica. As faixas etárias estão todas representadas: crianças, adolescentes e adultos, inclusive alguns idosos. Quanto à sua formação, há representação dos dois extremos, o licenciado e o analfabeto.

O trabalho distribui-se pelo setor agrícola, muitas vezes sazonal, em olivais e vinhas, sobretudo na zona da migração na região do Douro. Distribui-se ainda pelos setores das obras públicas e dos transportes. O migrante tem que ter trabalho para obter o registo de cidadão da Segurança Social. A falta de emprego leva a dificuldades económicas e sociais. A nível da Saúde a falta de Número de Identificação da Segurança Social (NISS) gera problemas no pagamento de consultas.

A maior parte dos imigrantes está sem as suas famílias e a habitar apartamentos partilhados, vivendo, por vezes, situações de interculturalidade intensa na partilha da casa. Os agentes locais têm narrativas repetidas relativamente à dificuldade em assegurar estas casas já que a comunidade local tende ao ceticismo no que diz respeito aos migrantes, sendo estes acusados a priori de pouco responsáveis.

Os ucranianos distinguem-se dos restantes migrantes por já estarem muito integrados nas comunidades locais, com crianças no sistema educativo português. Salienta-se a facilidade de aprendizagem de línguas estrangeiras por estes migrantes e a escolha de casas nos centros urbanos, enquanto os búlgaros, por exemplo, se concentram nos campos.

No passado, quando havia mais migrantes na zona, houve muitas trocas de experiências de convívio interreligiões, tendo sido celebrada uma missa ecuménica. Sem uma associação local de migrantes, o CLAII serve de mediador, sendo os atendimentos registados para se saber o benefício que trouxeram ao concelho.

Ao saber o que se passa e o porquê da passagem dos imigrantes, os agentes locais conseguem interagir comas comunidades migrantes da melhor forma.

\section{Discussão}

A interculturalidade pressupõe a educação democrática bem como a transcendência de fronteiras na procura da igualdade dos povos e das culturas. Por isso, identidade, homogeneidade e diversidade são eixos definidores da interculturalidade apesar do aparente conflito dos conceitos. Para promover a interculturalidade e proporcionar a desejada integração de grupos migrantes na sociedade atual, respeitando a multiplicidade, insistimos num trabalho interinstitucional construtivo e bem elaborado.

Neste território com decréscimo importante de migração desde o ano de 2009, a equipa de investigação está a aplicar metodologias sobretudo baseando-se em entrevistas - usando um instrumento de recolha de dados especificamente criado para melhor lidar com algumas situações delicadas. As entrevistas com as entidades, embora informativas e mesmo colaboradoras, são, contudo fontes de informação pouco diversas. Para conhecer melhor a realidade dos grupos falta ouvir a voz do próprio migrante e entender a sua perceção do apoio e da integração que lhes são oferecidos no território. Haverá ainda outros imigrantes que, por não procurarem ajuda, permanecem invisíveis nas estatísticas.

$\mathrm{Na}$ procura da interculturalidade que se revela e as caraterísticas de que se reveste, ainda não detetámos problemas específicos por resolver entre a comunidade local e os migrantes. Por enquanto, os casos especiais que nos deparámos são exclusivamente do foro das autoridades legais. No entanto e no caso de se detetarem problemas de conflito na comunidade, propõe-se a existência de um mediador intercultural, cuja função será de promover a comunicação entre os atores envolvidos, almejando a integração e a eventual resolução de conflitos. Esta interligação corresponderá à articulação desejada, que facilita o processo de integração efetiva dos migrantes bem como a promoção da interculturalidade.

As tendências significativas reveladas até agora remetem quase todas para as caraterísticas da própria 
comunidade local, fechada, parecendo haver um véu que dificulta a investigação nesta área. Os hábitos de pouca confiança entre os próprios agentes e o resultante desconhecimento acerca do que acontece noutras instituições pode resultar em mais dificuldades para este projeto de investigação.

As próximas fases já programadas envolvem expansão das entrevistas institucionais bem como a aproximação aos próprios migrantes para recolher o testemunho da sua experiência e a visão particular da interculturalidade. Também se pretendem desenvolver e divulgar os saberes e as experiências locais em encontros com a Rede no Ensino Superior para a Mediação Intercultural e o próprio ACM. Encontros com a comunidade local, envolvendo entidades, migrantes e académicos com o objetivo comum de melhor se conhecerem, refletindo sobre o possível intercâmbio de ideias e práticas, potenciarão os saberes e as práticas de mediação intercultural.

Continua, pois, a nossa procura de sinergias, ainda pouco visíveis, que fornecerão um maior esclarecimento sobre a interculturalidade na migração do distrito da Guarda.

\section{Referências}

ACIDI (2011). Migração: Portugal entre os países com melhores condições de acesso ao mercado de trabalho. 26.02. http://www.acidi.gov.pt/_cfn/4daf2abad571f/li ve/Ver+not\%C3\%ADcia+da+Lusa

ACM- Alto Comissariado para as Migrações (2015). http://www.acidi.gov.pt/http://www.acidi.gov .pt/

ADM Estrela - Associação de Desenvolvimento e Melhoramentos (2015).

www.admestrela.pt

AMI - Assistência Médica Internacional (2007). Dossier: Migrações (Partes I, II e III), 8-11; 10-13; 69. http://www.ami.org.pt/media/pdf/migracoes1.pdf, http://www.ami.org.pt/media/pdf/migracoes2.pdf, htt p://www.ami.org.pt/media/pdf/Migracoes3.pdf

Boudon, Raymond et all (1990). Dicionário de Sociologia. Lisboa: D. Quixote.

CLAII - Centros Locais de Apoio à Imigração (2015). http://www.acidi.gov.pt/esimigrante/servicos/centros-locais-de-apoio-a-

integracao-de-imigrantes---claii

Cronin, D. (2009). The EU should protect asylum seekers. The Guardian,
27.08 http://www.theguardian.com/commentisfree/lib ertycentral/2009/aug/27/eu-asylum-seekers

Falcão, C. \& Dinis, R. (2015). UE abre as portas a 20 mil imigrantes e vai combater redes de tráfico de seres humanos no terreno. $\mathrm{O}$ Observador, 13.05. http://observador.pt/2015/05/13/ue-abre-asportas-a-20-mil-imigrantes-e-vai-combater-redes-detrafico-de-seres-humanos-no-terreno/

European Commission (2015). Agenda for Migration.

Giménez Romero, C. (1997). La naturaleza de la mediación intercultural. Revista de Migraciones 2, 125-159.

Governo de Portugal (2015). Anabela Miranda Rodrigues no Conselho da UE que Debateu a Agenda para as Migrações. 16.06. http://www.portugal.gov.pt/pt/osministerios/ministerio-da-administracao-

interna/mantenha-se-atualizado/20150616-maimigracoes-ue.aspx

Lusa (2011). Migração: Portugal entre os países com melhores condições de acesso ao mercado de trabalho. $\mathrm{O}$ Público. 26.02. http://www.publico.pt/sociedade/noticia/migra cao-portugal-entre-os-paises-com-melhorescondicoes-de-acesso-ao-mercado-de-trabalho1491393

Pires. P. (1990)"Uma Teoria de Integração" in Sociologia- Problemas e Práticas, n³, 9-54.

Pop, V. (2015). EU to Propose Relocation of 40,000 Syrians, Eritreans From Italy and Greece. The Wall Street Journal, 26.05 http://www.wsj.com/articles/euto-propose-relocation-of-40-000-syrians-eritreansfrom-italy-and-greece-1432661922

Ribeiro, J.S. (2015). Mediação InterCultural e Território: conceitos e noções. Paper apresentado nas I Jornadas RESMI - Rede de Ensino Superior para a Mediação Intercultural: Entre diferentes e iguais, a mediação intercultural, 21.05.2015. Centro Ismaili, Lisboa.

Rocha-Trindade, M. (1995). Sociologia das Migrações. Lisboa: Universidade Aberta.

Silva, A.M.C., Piedade, A., Morgado, M. \& Arau Ribeiro, M.C. (2015). Mediação intercultural e território: estratégias e desafíos. Paper apresentado nas I Jornadas RESMI - Rede de Ensino Superior para a Mediação Intercultural: Entre diferentes e iguais, a mediação intercultural, 21.05.2015. Centro Ismaili, Lisboa. 